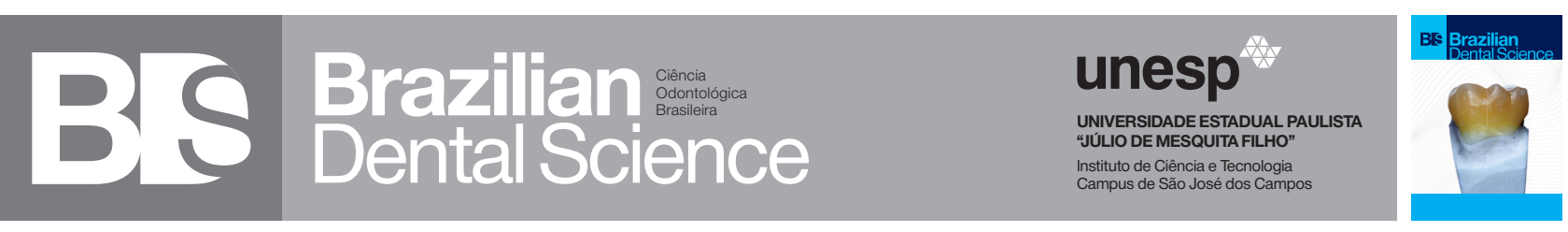

\title{
Biological Restorations: A foreseeable possibility in the junction between dentistry and technology
}

Restaurações Biológicas: Uma possibilidade previsível no encontro da Odontologia com a Tecnologia

\author{
Guilherme SAAVEDRA ${ }^{1,2}$, Diogo Miguel da Costa Cabecinha Pacheco VIEGAS ${ }^{2}$, Fabio COSTA ${ }^{3}$, Paulo KANO KA,5 $^{1,4}$ \\ 1 - São Paulo State University (Unesp) - Institute of Science and Technology, São José dos Campos - SP - Brazil. \\ 2 - School of Dental Medicine - University of Lisbon (FMDUL) - Portugal. \\ 3 - Centro Integrado Santa Cruz, CIESC - São Carlos - SP - Brazil. \\ 4 - Digital Dentistry Department - São Leopoldo Mandic - Campinas - SP - Brazil. \\ 5 - Department of Dentistry - Federal University of Santa Catarina (UFSC) - SC - Brazil.
}

\begin{abstract}
Prosthetic rehabilitation can generate doubts among professionals regarding the type of material to choose when planning rehabilitation treatments. The establishment of reliable criteria for material selection raises frequent questions. This work presents a concept and an alternative and simplified proposal to paradigm shift in therapeutic approaches based on three trends in restorative dentistry: Biomimetics, the use of natural tissue as a restorative material, which offers potential for the recovery of the mechanical, aesthetic and biological properties of teeth; digital dentistry and CAD/CAM systems; and adhesive technology, which has undergone exponential and impressive advances. However, further studies are needed to evaluate the long-term performance of restorations in this variable field.
\end{abstract}

\section{KEYWORDS}

Adhesion; Ceramics; Natural tooth; CAD/CAM; Oral rehabilitation; Biomimetics.

\section{RESUMO}

Muitas dúvidas surgem quanto ao tipo ideal de material restaurador a ser escolhido durante a elaboração do planejamento em tratamentos reabilitadores. Determinar critérios seguros para seleção do material são questionamentos frequentes. Este trabalho apresenta, por meio de um caso clínico, um conceito: restaurações biológicas e uma proposta alternativa e simplificada para quebrar paradigmas quanto a novas abordagens terapêuticas com as três tendências da Odontologia Restauradora Moderna: Biomimética - mimetizar e/ou utilizar o tecido natural dental como o material restaurador, com potencial de recuperar as propriedades mecânicas, estéticas e biológicas dos dentes danificados, a Odontologia digital e Sistemas CAD/CAM - com avanços exponenciais e a consagrada tecnologia adesiva. Porém mais estudos ainda são necessários para avaliar o desempenho a longo prazo dessas restaurações neste vasto campo de variabilidades.

\section{PALAVRAS-CHAVE}

Adesão; Cerâmicas; Dente natural; CAD/CAM; Reabilitação bucal; Biomimética. 


\section{INTRODUCTION}

$\mathrm{D}$ entistryhas experienced agreat transformation in which artificial intelligence techniques have greatly simplified the implementation of different procedures.

There has also been a reduction in the number of specialities as general practitioners have been able to use technology to perform procedures that have often been referred to specialists. These transformations are being experienced in various specialities, such as implantology, prosthodontics, endodontics, surgery and orthodontics.

These changes are taking place in a world in which teeth play an extremely important role in life. Partial and/or total tooth loss results in a significant decrease in the ability to eat, with undesirable consequences for overall health. In addition, compromised aesthetics can negatively affect one's social life. Both function and aesthetics can be restored with dental prostheses [1].

The selection of material for dental prostheses is represented by a vast field of research. The search for an ideal restorative material that behaves exactly like natural dental tissue and is able to repair, protect and re-establish the compromised natural structure is ongoing. It is known that natural teeth have mechanical performance and aesthetic characteristics that remain unmatched by the current restorative materials (polymers, ceramics and metal alloys) used for reconstruction $[2,3]$.

Much discussion has surrounded what material to select for restorative treatments, and questions regarding load transfer to the remaining tooth structure remain unsolved. "It is better to select harder and stronger materials, or on the contrary, to find treatment types that reproduce the biomechanical behaviour of the intact tooth structure" $[4,5]$.

Even when cracks in the enamel are observed, it does not suggest a deficiency of the restoration in response to trauma. A crack can be considered the result of a protective mechanism. The enamel-dentine junction is a slightly mineralised interface between two highly mineralised tissues (enamel/dentine).
There are parallel-oriented coarse collagen bundles (presumably the von Korff fibres of the mantle dentine) that form massive consolidations, which can divert and weaken enamel cracks by means of considerable plastic deformation $[6,7]$.

A significant number of resources have been devoted to bioengineering and stem cell research attempts to make a real tooth (enamel and dentine) "in a petri dish," but it is often forgotten that countless intact natural molars (wisdom teeth) and premolars are extracted and discarded on a daily basis due to impaction or for orthodontic reasons $[8,9]$.

Therefore, why not use those intact teeth as biological restorations?

In paediatric dentistry, approaches have been described that use biological restorations with autoclaved tooth fragments $\left(120^{\circ} \mathrm{C}\right.$ for 20 $\mathrm{min})$, positioned under incisors and primary molars with crowns that have been damaged by exteensive carious lesions [10-12].

The sterilisation of dental tissue is already possible and has emerged in research on natural teeth as a way to minimise the chances of cross-infection. This process could validate the use of such teeth in new and different intra- and interpatient tissue transfer techniques. Pachley et al. (1993) demonstrated that a sterilisation protocol did not change dentine permeability and bond strength. However, more studies are needed in this vastly variable field $[13,14]$.

Developments in three areas of restorative dentistry have contributed significantly to the quality of treatment and the possibility of using natural teeth as a restorative material: adhesive dentistry; computer aided design/ manufacturing (CAD/CAM) - digital dentistry; and biomimetics/bio-emulation (the study of the structure, function and biology of the natural tooth) $[15,16]$.

Adhesive dentistry has a well-established bonding adhesive technique, allowing nonretentive and minimally invasive preparations with techniques that are optimised for dentine bonding and offer immediate dentine sealing $[17,18]$. 
Digital dentistry has undergone exponential advances due to the significant progress of production devices and computer processing [19].

A specific example is the use of the SKIN concept, which replicates natural morphology realistically, responsively and predictably by applying technology to different materials (ceramics, polymers, metals, and even natural dental tissue). It can be used in several oral rehabilitation situations, reducing the number of important clinical and laboratory stages and eliminating the need for wax-ups when performing diagnostics and mock-ups. Known initially as AST (anatomic shell technique), the SKIN concept method is essentially agile and predictable and offers new options in various specialities. It faithfully reproduces the tooth's nature, with anatomical and functional details, and offers a personalised aesthetic according to the patient's choice. It is based on a morphology portfolio, which allows the unlimited creation of smiles through the numerous dental compositions, including the inherited transference of consanguineous patients. [20].

The literature suggests that in order to work agilely without losing quality and to ensure efficiency, speed and accuracy, it is necessary to combine technique and technology to enhance the workflow. The only way to produce interesting results is to be faithful to our concepts, principles and beliefs, where we strive to make a difference, achieve excellence and overcome the greatest of all challenges: replicating nature in all its perfection $[22,23]$.

Biomimetic and bio-emulation approaches allow the combination of a biological resource, such as third molars and premolars that have been extracted (for orthodontic reasons) from a donor, with a CAD/CAM system and adhesive technology to rehabilitate the original tooth's function, mechanical properties and aesthetics. An existing approach manual wearing of the tooth structure to achieve a certain degree of adjustment and adaptation. However, this is an empirical method that produces a poor fit in relation to the standards demanded from indirect restorations [24,25].

Magne et al., [9] described a technique for restoring a damaged to oth with a natural restoration obtained by milling an extracted third molar with CAD/CAM technology and reported a 4-year follow-up. The main benefit of this new technique is the accurate replacement of lost tissue with real enamel and dentine and the potential to recover mechanical, aesthetic and biological properties. The method's innovative quality lies in the optimal use of the extracted tooth substrate using the positioning technique in the CAD/CAM milling chamber.

This work aims to present and describe a clinical case planned and executed under alternative and simplified functional parameters that guided us in providing rehabilitation treatments with CAD/CAM technology to improve the accuracy of restorations using natural tissue from extracted teeth. As with synthetic material (ceramic and/or composite resins), natural dental tissue may be milled with high accuracy by a predictable process9. However, extra stages are needed to achieve correct disinfection and proper positioning of the sample for the milling stage, which leads to new possibilities in the dental rehabilitation area. It should be noted that the goal of any treatment is to preserve the remaining tooth structure and, as much as possible, to avoid discarding a natural dental organ without attempting to use it, based on scientific evidence and the principles of minimally invasive dentistry, to ensure longevity and clinical predictability.

\section{Clinical Case: Biological restoration - interpatient donation}

A healthy female patient, age 41 years, sought treatment at a private practice due to complaints about and dissatisfaction with her chewing ability and posterior dental aesthetics. During the clinical interview, the patient reported an inability to frequently visit a dental professional and the progression of chipping and fractures of the indirect restoration in recent years. The patient had no radiographic images that suggested lesions.

Intraoral photographs were taken to aid 
in planning and for record-keeping purposes.

Clinical examination revealed wear and fracture of the ceramic restoration on the occlusal surface of element 36 (Figure 1a,1b), with buccal dentine exposure consistent with an abfraction lesion. The patient reported that element 36 had been restored after the occurrence of dentine caries.

Treatment was planned to replace the indirect ceramic restoration with a restoration using natural dental tissue harvested from a donor patient (left lower third molar) (Figure 2 ), and used on a recipient patient in the same family (the donor patient's wife).

Both the recipient patient and the donor (husband - 42 years old) were told that this type of treatment with natural dental tissue and the CAD/CAM technique had been used in few studies, with limited citations in the literature. They consented to the proposed treatment, which was described to them in detail. After acceptance thereof, the treatment began.

The first stage entailed taking a digital impression of the donor patient's third molar (Figure 3), Images were captured using a TRIOS pen grip intraoral scanner (3Shape, Copenhagen K, Denmark) (38). The files, generated in stl format, were exported to the exocad dental CAD program (exocad, Darmstadt, Germany).

The same protocol was then used for the lower left 1st molar region (36) of the recipient patient (Figure 4a,4b). At this point, several factors were considered for study, and a prior evaluation of parameters such as mesiodistal and buccolingual distance, cervical occlusion and cervical diameter constriction is essential. It is important that the donor tooth is at least slightly larger in all parameters than the recipient area.

After establishing that it was possible to use the 3rd molar as the donor dental tissue, we removed the tooth 36 restoration and the non-retentive preparation, which had wear in the cervical direction due to enamel wear in this area. This was immediately followed by dentine sealing using a one-step adhesive (Adhese Universal, Ivoclar Vivadent, Liechtenstein). The preparations were refined with the use of a speed multiplier (T2 Line, Sirona, Germany) and Arkansas burs.

Next, a digital impression was taken using a TRIOS pen grip intraoral scanner (3Shape, Copenhagen K, Denmark) to capture the preparation in the recipient area (Figure 5). A \#00 retraction cord (Ultrapak, Ultradent, USA) was inserted into the gingival sulcus to facilitate visualisation and moisture control, with all the preparation located above the gingival margin.

The third molar (38) was extracted, cleaned by removing the periodontal tissue, and immediately immersed in saline. It was subsequently autoclaved $\left(120^{\circ} \mathrm{C}\right.$ for $\left.20 \mathrm{~min}\right)$ to minimise the chance of contact with possible contaminants.

A digital impression of the entire tooth, including the roots, was made using a TRIOS pen grip intraoral scanner (3Shape, Copenhagen K, Denmark) (Figure 6). The dental element was then cut $1 \mathrm{~mm}$ below the cementoenamel junction (Figure 7a,7b) and again immersed in saline.

This process (Figure 8, 9a and 9b) was supported by positioning the natural crown inside a custom milling block 19 (Figure 10a,10b), EMPRESS CAD Multi, colour A1, C14 (Ivoclar Vivadent, Liechtenstein) with IPS direct composite resin (Ivoclar Vivadent, Liechtenstein) and universal adhesive (Adhese Universal, Ivoclar Vivadent, Liechtenstein) (Figure 11). To this end, an initial block with the same specifications was milled without separating the crown from the ceramic block. An additional silicone mould (Virtual, Ivoclar/Vivadent, Liechtenstein) that included the occlusal surface was used to position the natural tooth crown in a new individualised L-shaped block. The new custom milling block glued to the natural crown was milled using the previous block with the natural tooth (biocopy/double scan). This prevented the occlusal surface of the natural tooth from being damaged by the milling tools and exposed only the surface where the preparation would set and the interproximal contact areas. Thus, all the anatomical characteristics of the occlusal and free surfaces were preserved, in accordance with the SKIN concept. 
For illustration and simple evaluation purposes, after the milling procedure, a conventional impression of the full upper arch was performed in two steps using addition silicone (Virtual, Ivoclar/Vivadent, Liechtenstein), and a gypsum model was obtained (Fujirock, GC, Japan) (Figure 12a, 12b, 12c).

Cervical marginal adaptation was considered acceptable.

The patient was not given a temporary restoration due to the short time between execution of the preparations and cementation $(2 \mathrm{~h})$.

After the test and evaluation, we proceeded with the cementing process (Figure 13a,13b,13c,13d). The preparation was cleaned with a brush and pumice, followed by application of $37.5 \%$ phosphoric acid (Ivoclar Vivadent, Liechtenstein) for 15 seconds on the dentine and $30 \mathrm{~s}$ on the enamel. The same $37.5 \%$ phosphoric acid was used to treat the restoration for $15 \mathrm{~s}$ for the dentine and $30 \mathrm{~s}$ for the enamel. Excite F (Ivoclar Vivadent, Liechtenstein) adhesive was also applied to the tooth preparation. The natural restoration was cemented with light-cured Variolink ${ }^{\circledR}$ Aesthetic (Ivoclar Vivadent, Liechtenstein), and excess cement was removed with Cavibrush brushes and dental floss. The cement was lightcured with $1200 \mathrm{~mW} / \mathrm{cm} 2$ exposure for $60 \mathrm{~s}$ (Bluephase, Ivoclar Vivadent, Liechtenstein).

The occlusal contacts were subsequently adjusted, the interproximal contacts were evaluated with dental floss, and excess adhesive and cement were removed with a periodontal curette. The cementation line was also treated with topical application of $5 \%$ sodium fluoride (Duraphat, Colgate, USA)(Figure 14a,14b). Three weekly control sessions took place without the need for intervention to evaluate the treatment and increase safety by extending the duration of the proposed experimental treatment.

The patient actively participated in the evaluation, planning and execution of the proposed stages.

Clinical Case: Biological restoration interpatient donation

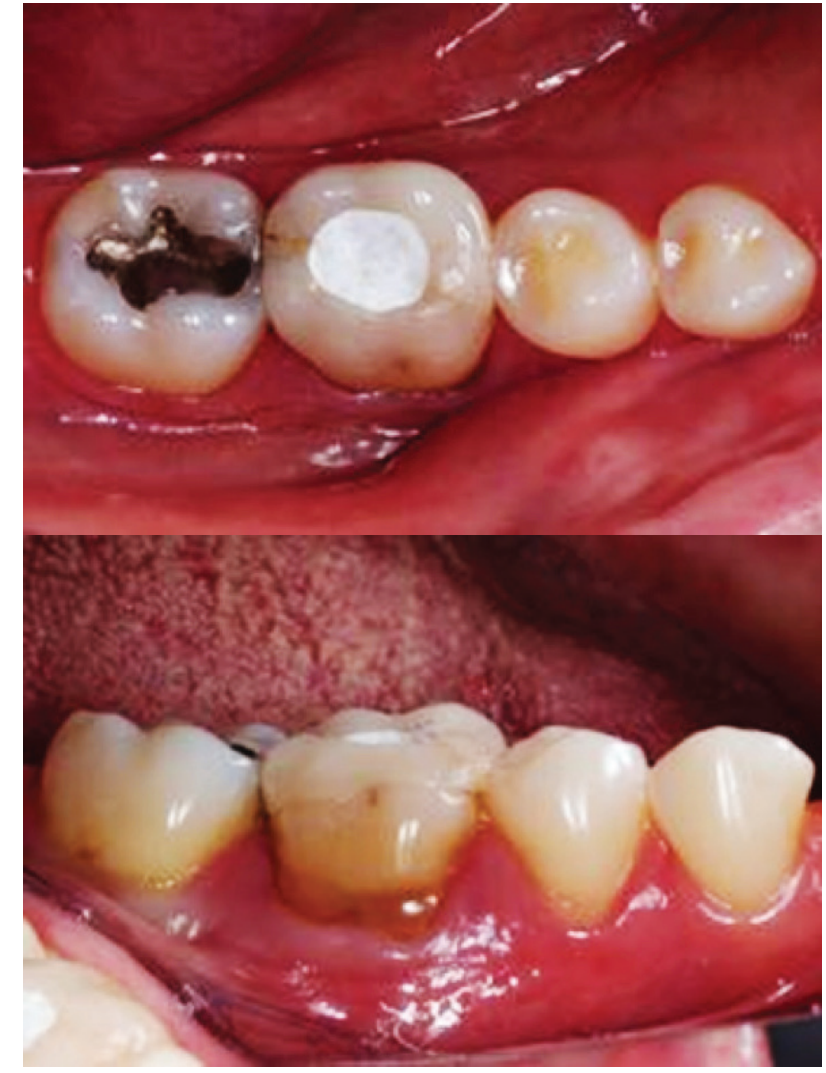

Figure 1 - A,B: Initial appearance of lower arch and element 36 to be restored (recipient).

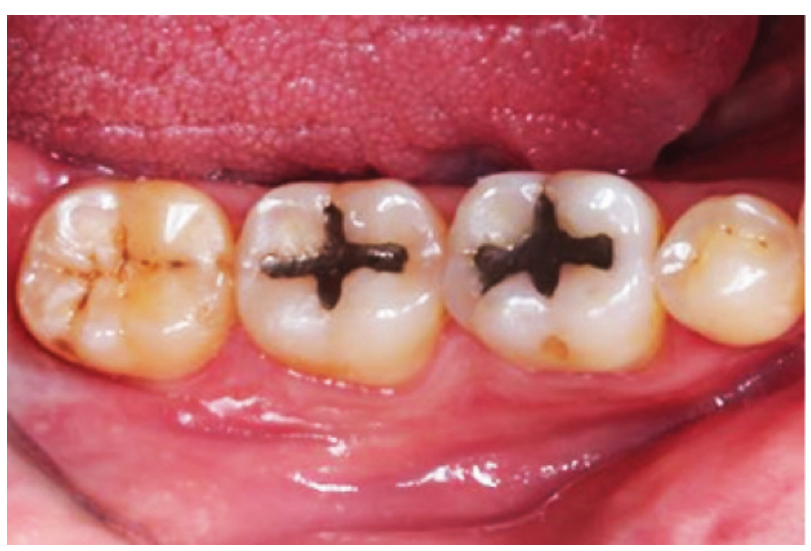

Figure 2 - Posterior quadrant. Initial appearance of donor element 38 (mirror). 


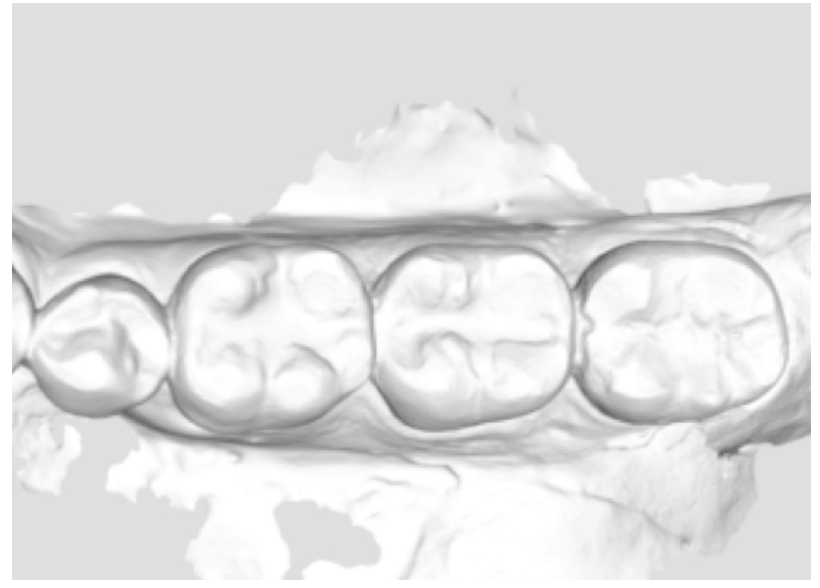

Figure 3 - Virtual image of the lower arch - donor area (element 38).

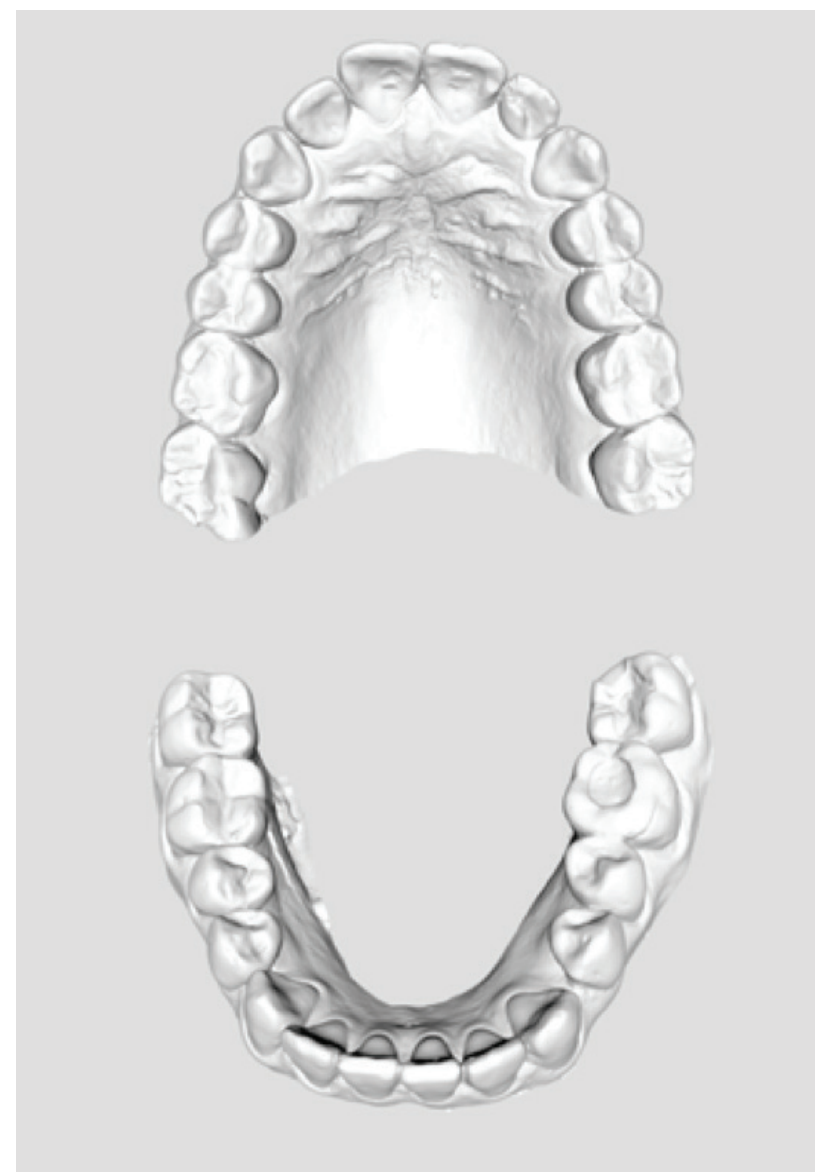

Figure 4 - A,B: Virtual image (.stl) of the recipient patient's upper and lower arches (36).

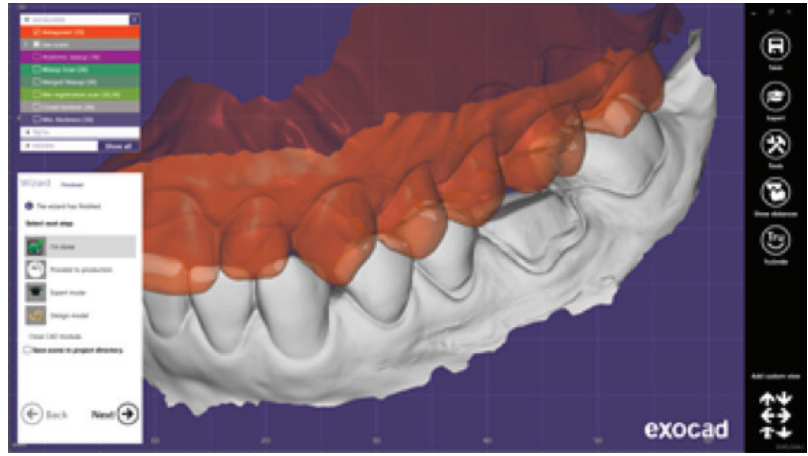

Figure 5 - Virtual image showing the scans of the recipient area after dental preparation and delineation of the preparation's cervical finish line.

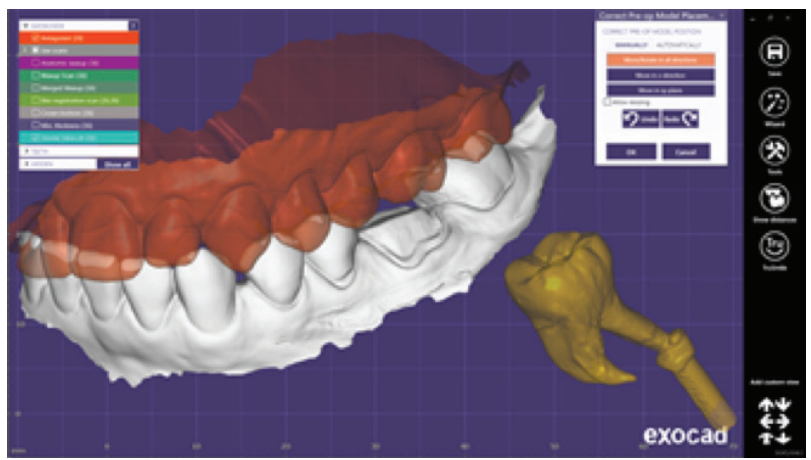

Figure 6 - Virtual image of donor's 3rd molar after extraction and image of 3rd molar already imported as a reference (biocopy) for the design of element 36.

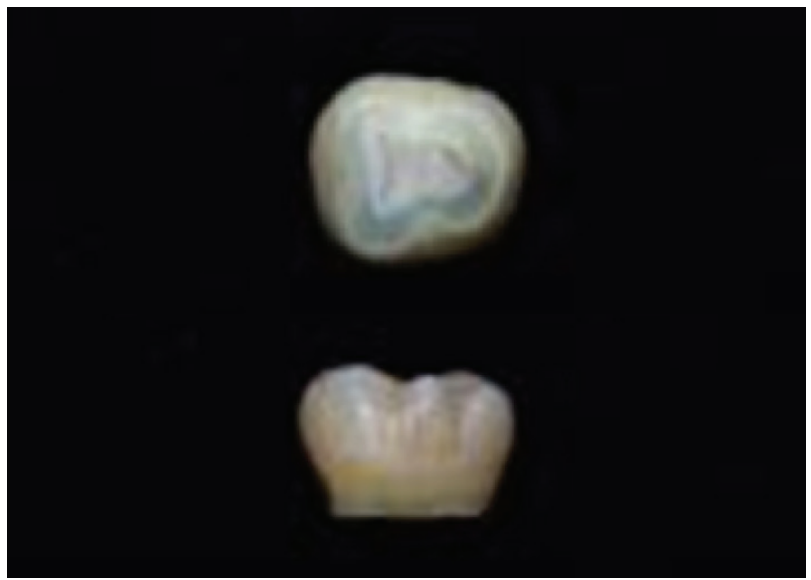

Figure 7 - A,B: Different views of the donor patient's element (38) after extraction and removal of the remaining root $1 \mathrm{~mm}$ below the cementoenamel junction. 


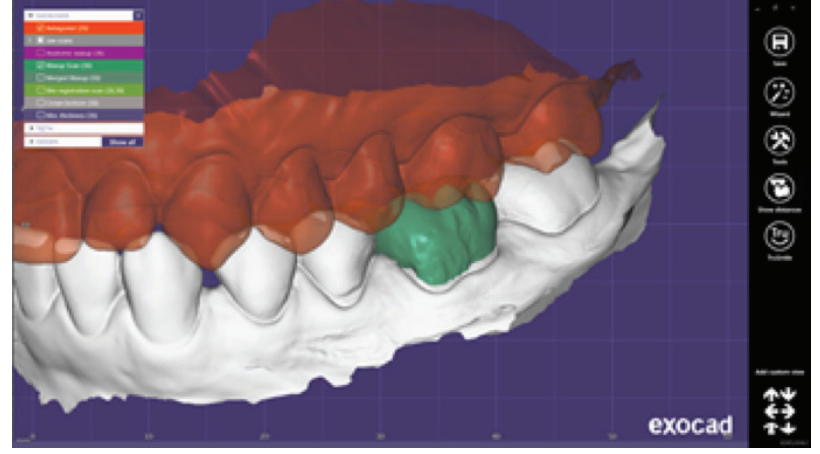

Figure 8 - Virtual image of digital restoration adapted and positioned on the digital recipient model followed by the final crown design, with reference to the occlusal contact intensity.
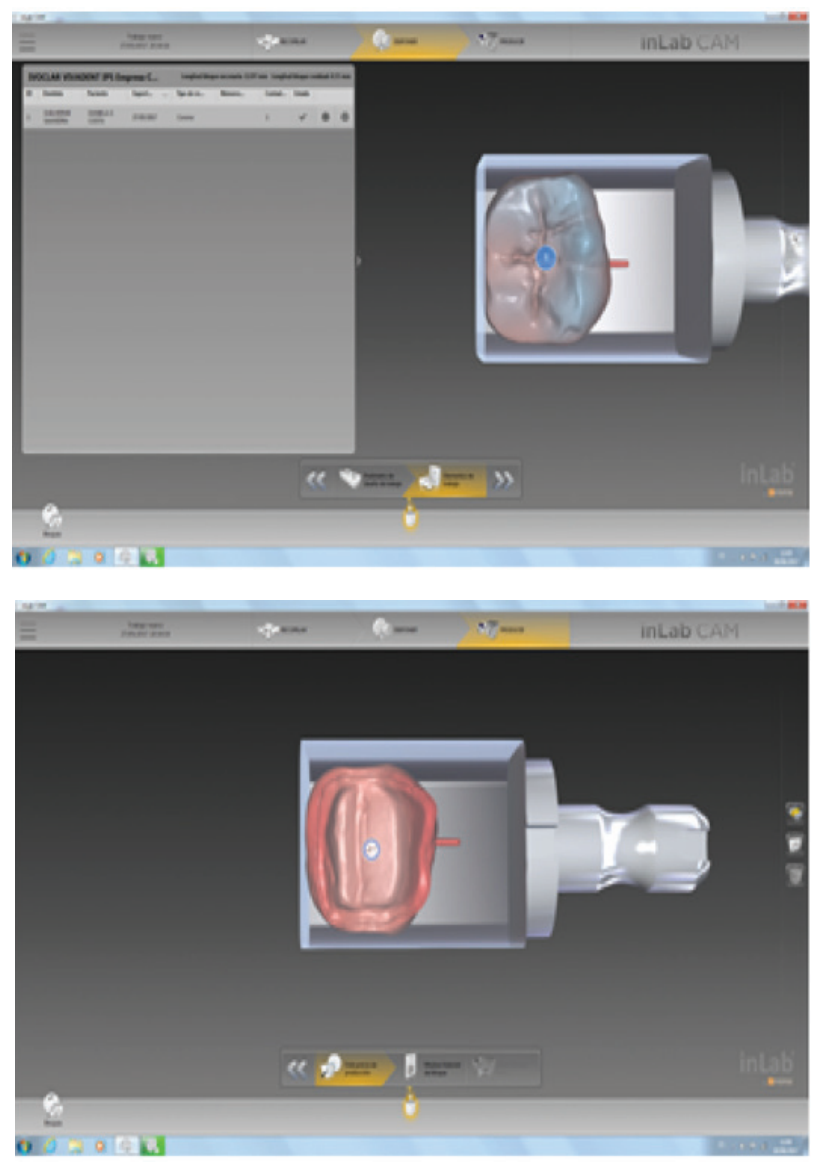

Figure 9 - A,B: Virtual image of the exported crown positioned on the virtual ceramic block (software in lab 16.0, Sirona, Germany) for the start of the milling stage.
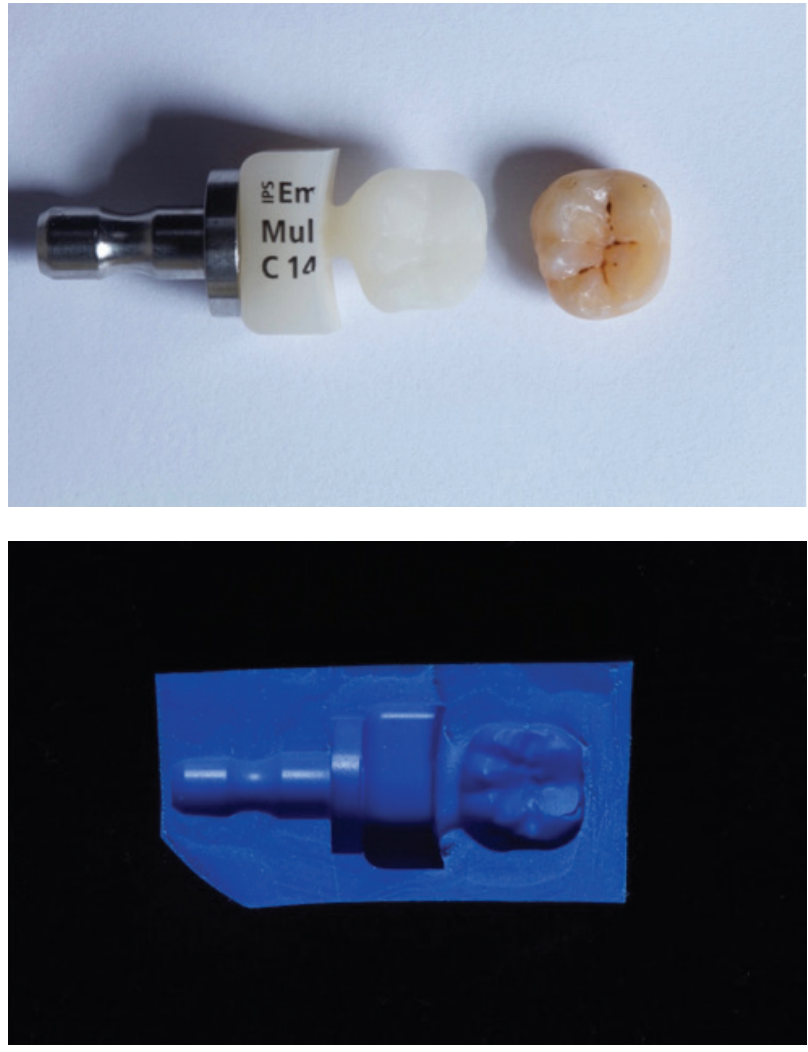

Figure 10 - A,B: Ceramic crown adjacent to its natural reference (CLLONES concept). Creation of addition silicone matrix to allow positioning of the natural tooth on the block prior to the second milling stage.

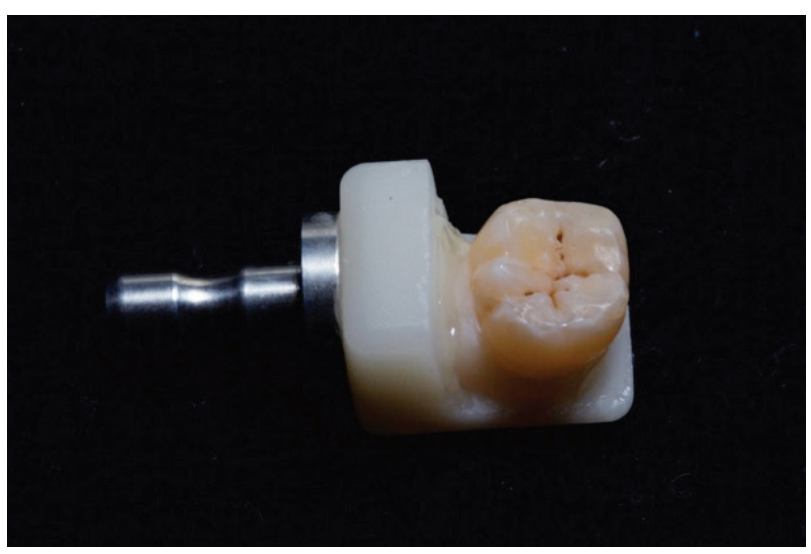

Figure 11 - The natural tooth's crown positioned on the ceramic block. 


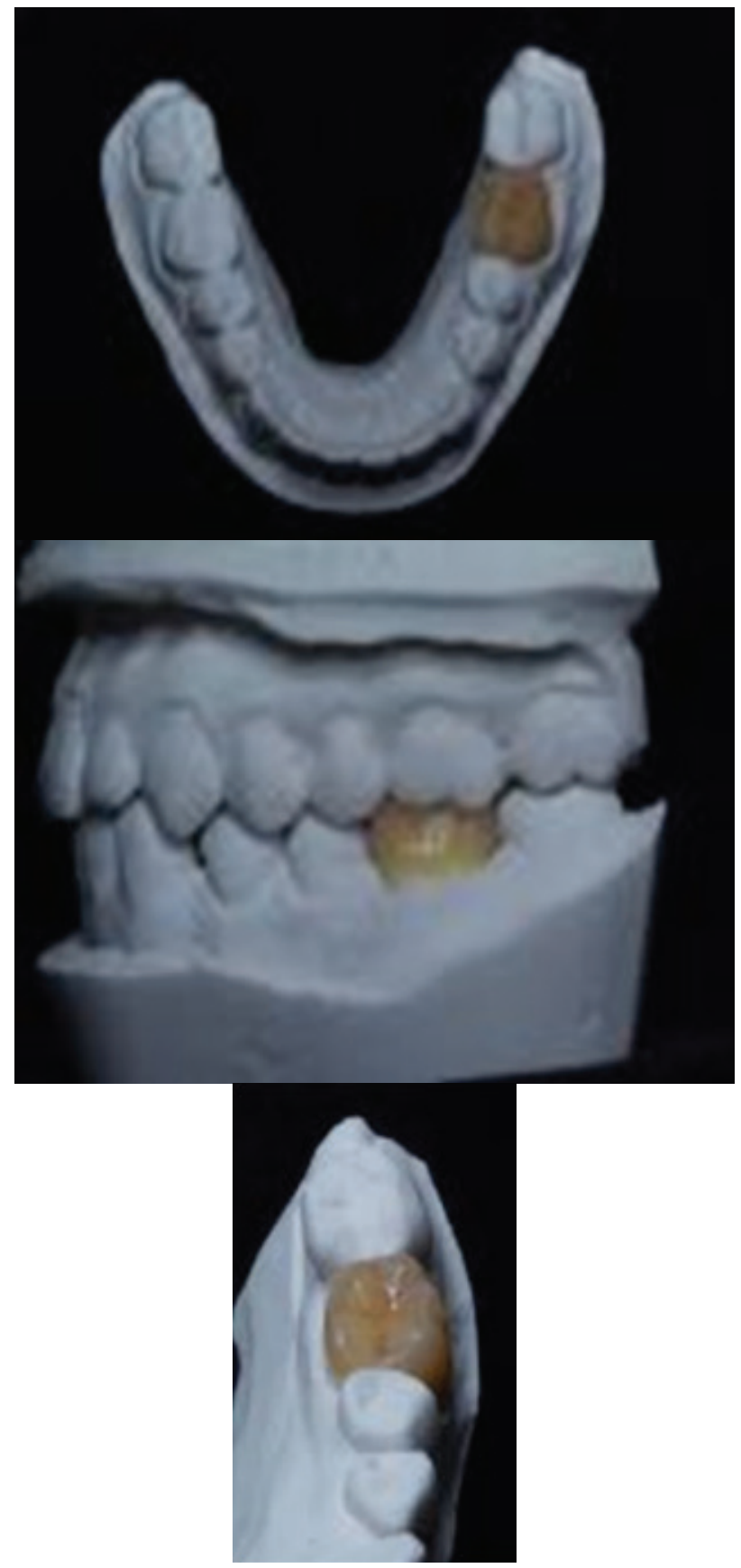

Figure 12 - A,B,C: Final images of the natural crown on the working model from different views.

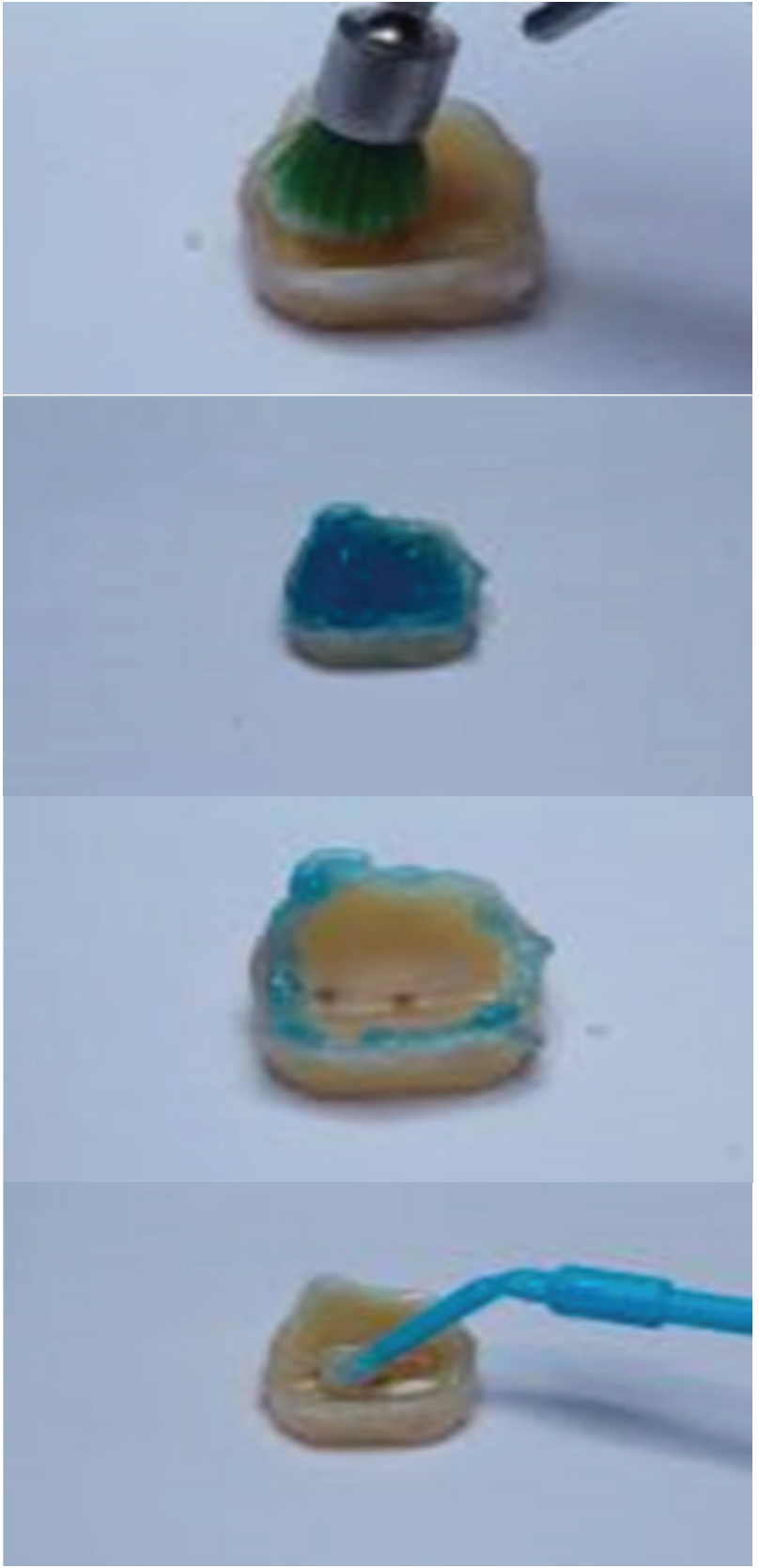

Figure 13 - A,B,C,D: Stages of surface treatment of the enamel and dentine with phosphoric acid (37.5\%) and Excite F bonding agent (Ivoclar Vivadent, Liechtenstein). 


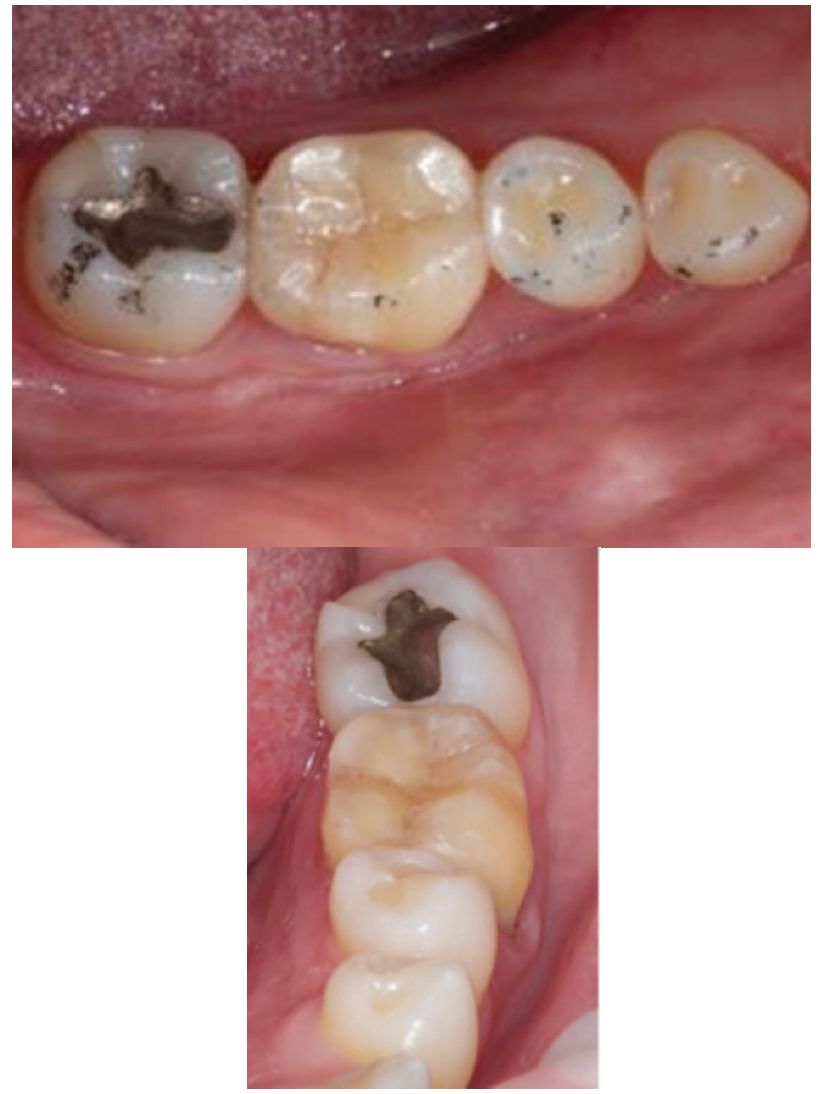

Figure 14 - A,B: Final images from different views of the natural tissue crown of element 38 (donor) cemented into the interpatient recipient area (36).

\section{DISCUSSION}

The search for an ideal restorative material that behaves completely the same as natural dental tissue and that can repair, protect and re-establish the compromised natural structure is ongoing. Many satisfactory options have been developed, but none perfectly reproduces the natural tooth structure.

Understanding the different types of clinical failures and their causes is a current need; to this effect, we can use laboratory studies to predict limitations in the properties of friable materials and suggest clinical procedures that may obtain better clinical behaviour from the selected materials [27].

On the other hand, laboratory work is rarely carried out with specimens that fully reproduce the clinical reality, and some conditions are often and purposefully ignored to reduce the inclusion of variables in research and facilitate the interpretation of results. These practical aspects of tests can mask the effect of some clinical factors, including the timedependent stress rate (slow growth of cracks), stress concentration, sample size effect and type of resulting failure [28].

The use of natural tissue may be an alternative for minimising these difficulties in exceptional cases. According to Schlichting et al. [19], there may be many reasons to support the use of natural restorations. The first is the ability of the enamel and dentine to biochemically interact with the oral environment during the demineralisation and remineralisation process. In addition to biocompatibility, another interesting advantage involves mechanical properties, in which case a crack maybe considered the result of a protective mechanism. The enameldentine junction is a slightly mineralised interface between two highly mineralised tissues (enamel/dentine). There are paralleloriented coarse collagen bundles (presumably the von Korff fibres of the mantle dentine) that form massive consolidations that can divert and weaken enamel cracks by considerable plastic deformation $[6,7]$.

Regarding optical characteristics, light dynamics are an important phenomenon in aesthetic restorations. The colour of the basal tooth is derived from the tooth's dentine, and the enamel functions as a modifier of the dentine colour. The enamel's thickness is a decisive factor for tooth colour. Human enamel is opalescent, which makes teeth blue under incident light and orange under transmitted colour. A scientific approach to the quantitative characterisation of the tooth's optical properties is necessary to develop and produce restorative materials that perfectly reproduce the optical properties of natural teeth. Another important factor to consider is that the colour of a tooth is determined by the path taken by the light within it and the light absorption along these paths. The paths taken by the light inside the 
tooth are determined by light dispersion, which, along with opacity and brightness, affect the tooth's perceived colour and appearance. When light hits a natural tooth, the interaction between the tooth and incident light can be described in terms of four phenomena: specular transmission, specular reflection at the surface, diffuse reflection at the surface and absorption and scattering within the tooth [26].

Also regarding optical characteristics, it is possible to perform whitening procedures on natural teeth; this is not possible with polymer and ceramic materials.

Another relevant factor is the availability of natural teeth that are extracted and discarded and may be used to restore remaining damaged teeth. The creation of tooth banks in Brazil could be an option to expand the use dental organs beyond laboratory work. However, biosecurity must be addressed.

Extracted teeth need to be sterilised to minimise the chances of cross-infection in laboratory research on natural teeth. This validates the use and even application of such teeth in new and different intra- and interpatient tissue transfer techniques. However, a great deal of research is needed to validate this type of work.

In paediatric dentistry, approaches have been described using biological restorations with tooth fragments that have been autoclaved $\left(120^{\circ} \mathrm{C}\right.$ for $\left.20 \mathrm{~min}\right)$ and positioned under incisors and primary molars with crowns that have been damaged by extensive carious lesions [10-12].

In regard to bonding, we know that enamel ensures predictability and that dentine, if treated according to protocols, can promote satisfactory bonding. Pachley et al. (1993) demonstrated that a sterilisation protocol did not change dentine permeability and bond strength. However, more studies are needed $[13,14]$. The emphasis on the survival of materials can take the focus off an important issue: the preservation of the dental structure [29-31]. A material may be stronger and have a high survival rate, but if it requires a more invasive preparation, the chances of biological complications are increased. On the other hand, if the material has very low longevity with failures that require restoration removal, the tooth will be submitted to new and repeated attacks.

However, what about when a prosthesis fracture? Does this always mean failure?

A possible, though controversial, means of repair is available. The use of CAD/CAM systems streamlines this repair process, as the restorations performed and stored in the CAD/ CAM system can be readily created to replace fractured ones. Nonetheless, the most important issue is that when the restoration material fails, the biological structure remains intact. Arguments vary, but changes in paradigms can be very welcome when there are conceptual differences in limitations and contraindications [28]. The SKIN concept replicates natural morphology more realistically, responsively and predictably by applying technology to different materials (ceramics, polymers, metals, and even natural dental tissue) [20,21].

Biomimetics and bio-emulation approaches allow the combination of biological resources, such as third molars and premolars that have been extract ed (for orthodontic reasons) from a donor, with a CAD/CAM system and adhesive technology to rehabilitate the original tooth function, mechanical properties and aesthetics. An existing approach entails manual wearing of the tooth structure to achieve a certain degree of adjustment and adaptation. However, this is an empirical method that produces a poor fit in relation to the standards demanded of indirect restorations $[9,24,25]$.

As proposed by Schlichting et al. [19] and Magne et al. [9], we treated two interpatient and intrapatient cases with the aid of CAD/ CAM technology and natural dental tissue from freshly extracted teeth. We confirmed the viability of the technique and the real possibility for the accurate replacement of lost tissue with dental enamel and dentine. 


\section{FINAL CONSIDERATIONS}

This study presented and described a planned experimental and clinical case involving the use of CAD/CAM technology to improve the accuracy of restorations and the use of natural tissue (enamel and dentine) from extracted teeth. This case provides a basis for discussions regarding material choice and represents a paradigm shift as it opens up new possibilities in the dental rehabilitation field. The great challenge for modern and conservative dentistry is to combine high levels of technical and material development with the predictability, reliability and longevity of clinical treatment supported by scientific evidence. It should be noted that the goal of any treatment is to preserve the remaining tooth structure and, as much as possible, to avoid discarding a natural dental organ without attempting to use it. It should also be noted that restoration failure should not be considered unsuccessful as long as the remaining dental structure is preserved.

\section{ACKNOWLEDGEMENTS}

The authors wish to thank the patients and the Ivoclar Vivadent Company for their valuable collaboration during the laboratory stages of the clinical cases.

\section{REFERENCES}

1. Madfa AA, Yue XG. Dental prostheses mimic the natural enamel behavio under functional loading: A review article. Jpn Dent SciRev. 2016 Feb;52(1):2-13. doi: 10.1016/j.jdsr.2015.07.001. Epub2015 Sep1.

2. Manhart J, Chen HY,Hamm G, Hickel R. Review of the clinical survival of direct and indirect restorations in posterior teeth of the permanent dentition. Oper Dent. 2004 Sep-0ct;29(5):481-508.

3. MagneP.Composite resins and bonded porcelain: the postamalgam era? J Calif Dent Assoc. 2006 Feb;34(2):135-47.

4. Magne P,Belser U. Bonded porcelain restoration in the anterior dentition: a biomimetic approach. Chigaco: Quintessence,2002.406p.

5. Fradeani M. Esthetic rehabilitation in fixed prosthodontics. Vol 1. Chicago: Quintecesse, 2004.352p.

6. Imbeni V, Kruzic JJ, Marshall GW, Marshall SJ, Ritchie RO. The dentin-enamel junction and the fracture of human teeth. Nat Mater.2005 Mar;4(3):229-32. Epub2005Feb 13.

7. Lin CP,Douglas WH, Erlandsen SL. Scanning electron microscopy of type I collagen at the dentin-enamel junction of human teeth. J Histochem Cytochem. 1993 Mar;41(3):381-8.
8. Esposito M, Coulthard P.Impacted wisdom teeth. BMJClin Evid. 2008 May 23;2008. pii: 1302.

9. Magne P,Schlichting LH. Biomimetic CAD/CAM restoration made of human enamel and dentin: case report at 4 th year of clinical service. Int J Esthet Dent. 2016;11(4):472-80

10. Barcelos R, Neves AA, Primo L, de Souza IP.Biological restorations as an alternative treatment for primary posterior teeth. J Clin Pediatr Dent. 2003 Summer;27(4):305-10.

11. Corrêa-FariaP,Alcântara CE, Caldas-Diniz MV, Botelho AM, Tavano KT. "Biological restoration": root canal and coronal reconstruction. J Esthet Restor Dent. 2010 Jun;22(3):168-77. doi: 10.1111/j.1708-8240.2010.00331.x.

12. Sanches K, de Carvalho FK, Nelson-Filho P,Assed S, SilvaFW, de Queiroz AM. Biological restorations as a treatment option for primary molars with extensive coronal destruction--report of two cases. Braz Dent J. 2007;18(3):248-52.

13. Pashley EL, Tao L, Pashley DH. Sterilisation of human teeth: its effect on permeability and bond strength. Am JDent. 1993 Aug;6(4):189-91.

14. Sandhu SV, Tiwari R, Bhullar RK, Bansal H, Bhandari R, Kakkar T, etal. Sterilisation of extracted human teeth: A comparative analysis. J Oral Biol Craniofac Res. 2012Sep-Dec;2(3):170-5.

15. Barcelos R, Neves AA, Primo L, de Souza IP. Biological restorations as an alternative treatment for primary posterior teeth. J Clin Pediatr Dent. 2003 Summer;27(4):305-10.

16. Sanches K, de Carvalho FK, Nelson-Filho P,Assed S, Silva FW, de Queiroz AM Biological restorations as a treatment option for primary molars with extensive coronal destruction--report of two cases. Braz Dent J. 2007;18(3):248-52.

17. Magne P,So WS, Cascione D. Immediate dentin sealing supports delayed restoration placement. J Prosthet Dent. 2007 Sep;98(3):166-74.

18. Nicholson JW. Biological considerations. In: Summitt JB, Robbins JW, Hilton TJ, Schwart RS, dos Santos J (eds). Fundamentals of Operative Dentistry: A Contemporary Approach. 3ed. Chicago: Quintessence Publishing, 2006. p1-36.

19. Schlichting LH, Schlichting KK, Stanley K, Magne M, Magne P.An approach to biomimetics: the natural CAD/CAM restoration: a clinical report. J Prosthet Dent. 2014 Feb;111(2):107-15. doi: 10.1016/j.prosdent.2013.08.006. Epub2013 Dec 17.

20. Kano P. The anatomical shell technique: an approach to improve the esthetic predictability of CAD/CAM restorations. In: Quintessence of Dental Technology. Vol36. Quintessence Publishing Co.2013. p27-36.

21. Saavedra G. Skyn Concept: Agilidade e previsibilidade sem perder a qualidade. Prótese News. 2017;4(1):401-5.

22. Sillas D. Editorial. In Quintessence of Dental Technology. Quintessence Publishing C0.2013, p2.

23. Du J, Niu X, Rahbar N, Soboyejo W. Bio-inspired dental multilayers: effects of layer architecture on the contact-induced deformation. Acta Biomater. 2013 Feb;9(2):5273-9. doi: 10.1016/j.actbio.2012.08.034. Epub2012 Aug 28.

24. Lee YK. Opalescence of human teeth and dental esthetic restorative materials. Dent Mater J. 2016 Dec 1;35(6):845-854. Epub 2016 Aug 20.

25. Kelly JR. Perspectives on strenght. Dent Mater. 1995 Mar;11(2):103-10.

26. Saavedra G,Anami LC, Francci CE. Laminados cerâmicos anteriorese posteriores em paciente com desordem functional estabilizada. Prótese Nnews. 2016;3(2):14-27.

27. Beier US, Kapferer I, Burtscher D, Dumfahrt H. Clinical performance of porcelain laminate veneers for up to 20 years. Int JProsthodont. 2012 JanFeb;25(1):79-85 
28. Layton DM, Clarke M, Walton TR. A systematic review and meta-analysis of the survival of feldspathic porcelain veneers overs 5 and 10 years. Int $J$ Prosthodont.2012 Nov-Dec;25(6):590-603.
29. WolfartS, Wegner SM, Al-Halabi A, Kern M. Clinical evaluation of marginal fit of a new experimental all-ceramic system before and after cementation. Int $J$ Prosthodont. 2003 Nov-Dec;16(6):587-92.

\section{Guilherme Saavedra}

(Corresponding address)

Visiting Professor, School of Dental Medicine, University of Lisbon (FM-

DUL) - Portugal; Vice President, Brazilian Digital Dentistry Society SBODigital.

Date submitted: 2019 Jul 19

E-mail: guilherme.saavedra@unesp.br 